\title{
黔中喀斯特木本植物功能性状变异及其适应策略
}

\author{
钟巧连1,2,3 刘立斌1,2,4 许 釒金 ${ }^{1,2,3}$ 杨 勇 $1,2,3$ 郭银明 $1,2,3$ 许海洋1,2,3 \\ 蔡先立 ${ }^{1,2,3}$ 倪 健 ${ }^{1,2,4^{*}}$
}

${ }^{1}$ 中国科学院地球化学研究所环境地球化学国家重点实验室, 贵阳 550081; ${ }^{2}$ 中国科学院普定喀斯特生态系统观测研究站, 贵州普定 $562100 ;{ }^{3}$ 中国科 学院大学, 北京 100049 ; $^{4}$ 浙江师范大学化学与生命科学学院, 浙江金华 321004

摘 要 性状变异反映了植物的生活史对策。该研究以贵州普定县天龙山 10 种木本植物为对象, 通过分析枝叶和根系 9 个功 能性状的种间与种内变异, 揭示植物对喀斯特生境的适应策略。结果表明: (1) 9个性状变异程度不同, 细根组织密度的种间和 种内变异系数最大, 分别达 $96.47 \%$ 和 $51.44 \%$, 小枝干物质含量的种间与种内变异最小, 分别为 $11.67 \%$ 和 $6.83 \%$ 。(2)种间水平 的细根组织密度在不同物种中没有显著的差异, 比根长、叶厚度、叶面积、比叶面积、叶干物质含量、叶组织密度、小枝干 物质含量和小枝组织密度均表现出显著的差异。在种内, 比叶面积差异显著, 其他性状差异不显著。(3)绝大多数叶和枝性状 间显著相关, 比根长与比叶面积显著负相关, 其他根系性状与枝叶性状相关性不显著。总之, 与同纬度非喀斯特地区植物相 比, 普定喀斯特地区植物具有较小的叶面积和比根长度, 较大的叶干物质含量、叶组织密度等一系列有利于减小蒸腾和储存 养分的功能性状组合, 这可能是其适应干旱贫癒的喀斯特环境的主要生态策略。

关键词 喀斯特森林; 生活型; 生长型; 性状组合; 种内变异; 种间变异

钟巧连, 刘立斌, 许金场, 杨勇, 郭银明, 许海洋, 蔡先立, 倪健 (2018). 黔中喀斯特木本植物功能性状变异及其适应策略. 植物生态学报, 42, 562-572. DOI: $10.17521 /$ cjpe.2017.0270

\section{Variations of plant functional traits and adaptive strategy of woody species in a karst forest of central Guizhou Province, southwestern China}

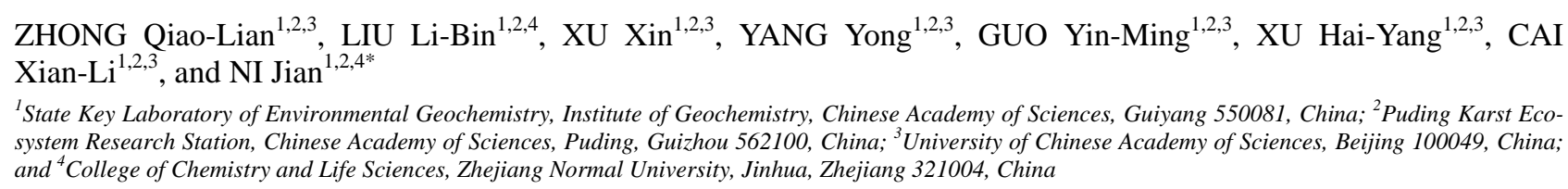

\section{Abstract}

Aims The aims are to characterize key plant functional traits and their interactions of woody species growing in special and harsh karst habitats, and to explore their potential ways in adapting harsh karst habitats.

Methods A comprehensive survey of nine plant functional traits (including above- and below-ground ones) was conducted in a $100 \mathrm{~m} \times 30 \mathrm{~m}$ permanent plot in the Tianlongshan Mountain of Puding County, central Guizhou Province, southwestern China in the summer 2016. Five dominant tree species (Carpinus pubescens, Machilus cavaleriei, Itea yunnanensis, Platycarya strobilacea, Lithocarpus confinis), three shrubs (Zanthoxylum ovalifolium, Stachyurus obovatus, Rhamnus heterophylla) and two vines (Rosa cymosa and Dalbergia hancei) in an evergreen and deciduous broadleaved mixed forest were chosen as target species. Nine traits of leaf, stem, branch and root were investigated and measured. Key features of these nine functional traits of ten woody species were numerically characterized. Traits variations among plant species, life form and leaf phenology group were further investigated. Relationships among key functional traits and between above- and below-ground traits were statistically analyzed.

Important findings (1) Nine traits varied in varying degrees. The maximum and minimum coefficient of interspecific variation were the fine root tissue density (FRTD) and twig dry-matter content (TDMC), 96.47\% and $11.67 \%$, respectively. Similarly, the largest and smallest coefficients of intraspecific variation were also FRTD and

收稿日期Received: 2017-10-29 接受日期Accepted: 2018-03-27

基金项目: 国家自然科学基金(41471049)和国家全球变化重大科学研究计划项目(2013CB956704)。Supported by the National Natural Science Foun-

dation (41471049), and the National Key Basic Research Program for Global Change (2013CB956704).

* 通信作者Corresponding author (nijian@zjnu.edu.cn) 
TDMC, 51.44\% and 6.83\%, respectively; (2) At the interspecific level, among different species FRTD had no significant difference, but other traits including specific root length $(S R L)$, leaf thickness $(L T)$, leaf area $(L A)$, specific leaf area (SLA), leaf dry-matter content (LDMC), leaf tissue density (LTD), TDMC and twig tissue density (TTD) showed significant differences $(p<0.01)$. At the intraspecific level, however, SLA showed significant difference, and differences of other traits were not significant. (3) There was a significant correlation between most leaf and branch traits, and $S R L$ vs. SLA were negatively correlated. However, there was no significant correlation among other root traits and leaf and twig traits. In a word, compared to the functional traits in tree species of non-karst evergreen broad-leaved forests in the same latitude, karst woody plants in Puding had a series of functional traits, such as smaller $L A, S L A$ and larger $L D M C$ and $L T D$ and so on, which are beneficial to reducing transpiration and storing nutrient. This may be its main ecological strategy for adapting to arid and poor karst environments.

Key words karst forest; life form; growth form; trait combination; intraspecific variation; interspecific variation

Zhong QL, Liu LB, Xu X, Yang Y, Guo YM, Xu HY, Cai XL, Ni J (2018). Variations of plant functional traits and adaptive strategy of woody species in a karst forest of central Guizhou Province, southwestern China. Chinese Journal of Plant Ecology, 42, 562-572. DOI: $10.17521 /$ cjpe.2017.0270

功能性状是指与植物对资源的吸收、利用和保 持有关的生理生态指标, 它反映植物对不同环境的 适应及植物内部不同功能之间的生理或进化的权衡, 是联系植物、环境和生态系统功能的桥梁(Reich et al., 2003; Díaz et al., 2004, 2016; 孟婷婷等, 2007; Violle et al., 2007)。叶片、枝干和根系性状及其组 合反映了植物对资源的利用和对环境的响应与生存 对策(Eissenstat et al., 2000; Lavorel \& Garnier, 2002; Westoby et al., 2002; Wright et al., 2004; Chave et al., 2009)。

植物性状间既有关联 (Wright et al., 2004; Walker et al., 2014)又有分离(Albert et al., 2010; Violle et al., 2012; Díaz et al., 2016)。作为植物光合 作用的叶片性状与作为吸收水分和养分的根系性状 是密切相关的(Craine et al., 2005), 作为植物生长重 要构件的枝干性状与叶片、根系性状间也相关 (Messier et al., 2017)。这些相互关联的植物性状在 适应环境的过程中会表现出不同的权衡策略, 比如 “投资-收益”的权衡(Laughlin, 2014; Verheijen et al., 2016; Messier et al., 2017)。

另一方面, 植物功能性状在种间和种内的变异 是物种共存、群落构建的重要前提(Díaz et al., 2004; Violle et al., 2012), 对植物个体、功能群、群落和生 态系统水平以及区域和全球尺度的研究发现, 不同 群落间、群落内乃至功能群内的种内与种间性状变 异可更真实地反映物种对环境变化和资源竞争的响 应(Wright et al., 2004; Albert et al. 2010), 而且种内 变异与种间变异同等重要(Auger \& Shipley, 2013; Bu et al., 2017), 这对基于性状的群落与生态系统研 究具有重大的实践指导意义(Siefert et al., 2015)。因
此, 植物各器官性状之间表现出普遍的相关性与变 异性, 进化背景和环境变化驱动植物的性状变异, 并通过一系列功能性状组合和权衡来适应环境, 从 而决定植物的生长对策(Reich et al., 2003; Stahl et al., 2013)。

喀斯特植被是一种具有特殊结构和功能的生态 系统, 生态敏感度高, 环境容纳量低, 稳定性差(王 世杰等, 2003), 在我国南方连续、成片分布的石灰 岩和白云岩地区表现最为典型, 以贵州、广西和云 南最具代表性。由于喀斯特地貌和石灰土的独特性, 导致该地区的代表性植被不是气候顶极的亚热带常 绿阔叶林, 而是隐域性、土壤顶极的常绿与落叶阔 叶混交林, 且在强烈的、不同方式人类活动干扰下, 次生林、藤刺灌从和灌草丛植被占据优势。适应于 喀斯特生境的植物表现出独特的喜䥻性、耐痊性、 岩生性等生理学和生态学特性(郭柯等, 2011)。

在贵州中部、重庆中梁山、桂林等喀斯特地区 开展的植物叶片性状研究发现, 不同地区植物叶性 状在种间和种内均存在较大差异(习新强等, 2011; 刘宏伟等, 2014, 2015; Jiang et al., 2016), 喀斯特地 区植物普遍呈现出比叶面积 $(S L A)$ 和叶面积 $(L A)$ 低、 叶干物质含量 $(L D M C)$ 高的性状组合。这种性状组合 意味着, 植物为适应喀斯特土层浅薄、土壤水分渗 漏等生境特征所造成的生理干旱, 趋向于发展一套 干旱性状组合。另外, 干旱地区的研究表明, 植物通 常以较厚的叶片适应水分胁迫, 例如叶片革质, 比 叶面积小, 叶片体积也随之减小, 导致叶组织密度 (LTD)增大, 并且通常有较大的比根长 $(S R L)$, 表明 在同等投资的情况下, 比根长大的植物对养分的利 用效率较高(Reich et al., 1998; Ohashi et al., 2006)。 
但是, 以上植物在适应干旱㾑薄生境过程中所形成 的叶片、枝干和根系器官间的性状组合是否也存在 于喀斯特地区的植物? 对这个问题尚需深入探索。

本文选取贵州省典型喀斯特地区的代表性常绿 与落叶阔叶混交林的优势乔木、灌木和藤本为研究 对象, 测定其枝干、叶片和根系性状, 研究喀斯特优 势种地上和地下性状的特征及其种间与种内变异, 以及地上和地下性状的相互关系, 以期探讨两个科 学问题: 喀斯特地区植物采取何种干旱性状组合及 生存对策来适应严酷的喀斯特生境? 地上和地下性 状及其相互关系是否与地带性常绿阔叶林植物存在 差异?

\section{1 研究方法}

\section{1 研究地概况}

研究地位于贵州中部的普定县马关镇下坝村天 龙山 $\left(26.24^{\circ} \mathrm{N}, 105.76^{\circ} \mathrm{E}\right.$, 海拔 $\left.1550 \mathrm{~m}\right)$, 为中国科 学院地球化学研究所普定喀斯特生态系统定位观测 研究站所在地, 属长江与珠江分水岭处的高原面型 喀斯特地貌。该地属中亚热带季风湿润性气候, 据 普定县气象站1961-2013年的记录, 年平均气温为 $15.2{ }^{\circ} \mathrm{C}, 1$ 月平均气温 $5.2{ }^{\circ} \mathrm{C}, 7$ 月平均气温 $23.0{ }^{\circ} \mathrm{C}$, 年降水量1341 mm, 年日照时间仅1 $189 \mathrm{~h}$, 全年日 照百分率低至26\%。母岩为石灰岩, 岩石裸露率平 均达 $34.7 \%$ 。土壤以棕色石灰土为主。

植被类型为次生性但保存相对较好的常绿和落 叶阔叶混交林。乔木层高度 $6-10 \mathrm{~m}$, 平均胸径 $5.4 \mathrm{~cm}$, 盖度 73.1\%左右, 优势树种包括窄叶石柇(Lithocarpus confinis)、化香树(Platycarya strobilacea)、云
南鼠刺 (Itea yunnanensis)、安顺润楠 (Machilus cavaleriei)和云贵鹅耳枥(Carpinus pubescens), 常见 树种还有短蓦海桐(Pittosporum brevicalyx)和香叶树 (Lindera communis)等。灌木层一般3 m以下, 盖度 $30 \%$ 左右, 常见种有倒卵叶旅节花(Stachyurus obovatus)、异叶鼠李 (Rhamnus heterophylla)、铁仔 (Myrsine africana) 以及多种花椒属(Zanthoxylum)植 物。草本层高度一般50 cm以下, 盖度20\%左右, 主 要物种有矛叶荩草(Arthraxon lanceolatus)和千里光 (Senecio scandens)等。群落层间植物发达, 某些藤本 植物如藤黄檀(Dalbergia hancei)胸径可超过10 cm, 长度可达40 m (Liu et al., 2016)。

2016年7-9月, 在天龙山山腰至山顶设置一块 $30 \mathrm{~m} \times 100 \mathrm{~m}$ 的样地, 划分为 30 个 $10 \mathrm{~m} \times 10 \mathrm{~m}$ 的小 样方, 调查并记录样方中胸径大于 $1 \mathrm{~cm}$ 的所有木本 植物的相对位置、胸径、高度和冠幅等指标。

\section{2 植物性状测定}

选择优势乔木 5 种、灌木 3 种和藤本植物 2 种, 每 种20-25株作为研究对象(表1)。在每株树冠外层的 东南西北 4 个方向, 采集全光照条件下无病虫害与 附生植物的完整枝条4根。在每根枝条上采集叶片 5-6个，保证每株乔木取20-30个叶片，每株灌木和 藤本植株取20-60个叶片。利用WinFOLIA多用途叶 面积仪(Regent Instruments, Québec, Canada)扫描叶 片, 获得其面积、长宽比等指标。将叶片置入烘箱 中, 先在 $105{ }^{\circ} \mathrm{C}$ 下杀青 $20 \mathrm{~min}$, 然后在 $85{ }^{\circ} \mathrm{C}$ 下烘干 $48 \mathrm{~h}$, 称取干质量。截取 4 根小枝末端20-30 cm称取 鲜质量, 烘干后再称干质量。截取小枝2-3 cm, 去掉 树皮，用排水法测定其体积。

表1 黔中喀斯特常绿与落叶阔叶混交林的 10 种优势木本植物

Table 1 The selected ten dominant woody species in a karst evergreen and deciduous broad-leaved mixed forest in central Guizhou Province, China

\begin{tabular}{|c|c|c|c|c|}
\hline $\begin{array}{l}\text { 物种 } \\
\text { Species }\end{array}$ & $\begin{array}{l}\text { 生长型 } \\
\text { Growth form }\end{array}$ & $\begin{array}{l}\text { 生活型 } \\
\text { Life form }\end{array}$ & $\begin{array}{c}\text { 采样株数 } \\
\text { Sample individuals }\end{array}$ & $\begin{array}{l}\text { 叶质地 } \\
\text { Leaf texture }\end{array}$ \\
\hline 安顺润楠 Machilus cavaleriei & 乔木 Tree & 常绿 Evergreen & 20 & 革质 Leathery \\
\hline 云南鼠刺 Itea yunnanensis & 乔木 Tree & 常绿 Evergreen & 20 & 薄革质 Thinly leathery \\
\hline 窄叶石栋 Lithocarpus confinis & 乔木 Tree & 常绿 Evergreen & 21 & 厚纸质 Thickly papery \\
\hline 化香树 Platycarya strobilacea & 乔木 Tree & 落叶 Deciduous & 25 & 纸质 Papery \\
\hline 云贵鹅耳枥 Carpinus pubescens & 乔木 Tree & 落叶 Deciduous & 20 & 厚纸质 Thickly papery \\
\hline 刺异叶花椒 Zanthoxylum ovalifolium & 灌木 Shrub & 常绿 Evergreen & 20 & 革质 Leathery \\
\hline 倒卵叶旌节花 Stachyurus obovatus & 灌木 Shrub & 常绿 Evergreen & 20 & 革质或亚革质 Leathery or subcoriaceous \\
\hline 异叶鼠李 Rhamnus heterophylla & 灌木 Shrub & 常绿 Evergreen & 20 & 纸质 Papery \\
\hline 小果蓄薇 Rosa cymosa & 藤本 Liana & 常绿 Evergreen & 20 & 薄纸质 Thinly papery \\
\hline 藤黄檀 Dalbergia hancei & 藤本 Liana & 落叶 Deciduous & 20 & 膜质 Membranous \\
\hline
\end{tabular}

www.plant-ecology.com 
选取乔木和藤本植株的一条主根, 以及灌木的 整个根系, 全部挖出。按照细根 $($ 根径 $\leqslant 2 \mathrm{~mm}$ )、中 根 $(2 \mathrm{~mm}<$ 根径 $<10 \mathrm{~mm})$ 、粗根 $(\geqslant 10 \mathrm{~mm})$ 进行分类, 洗净晾干后称取鲜质量。利用相同扫描仪扫描细根, 获得根系长度、表面积、总体积、平均直径等指标。 各取不同根径级根系, 利用排水法测定其体积。最 后, 将根系在 $85{ }^{\circ} \mathrm{C}$ 恒温下烘干称取干质量。

植物枝干、叶片和根系的性状指标按照以下公 式(Cornelissen et al., 2003)计算:

$S L A=$ 新鲜叶片面积/叶片干质量。

避开中间大叶脉, 利用精度为 $0.01 \mathrm{~mm}$ 的游标 卡尺测量叠在一起的 5 个叶片厚度。叶片厚度 $(L T)=$ 5 个叶片总厚度 $/ 5$ 。

$L D M C=$ 叶干质量/鲜质量。

$S R L=$ 根长/根干质量。

小枝干物质含量 $(T D M C)=$ 小枝干质量/鲜质量。

组织密度 $(T D)=$ 干质量/体积。 $L T D=$ 叶干质量/ 叶体积, 其中, 叶体积 $=$ 叶面积 $\times$ 叶厚度; 细根组织 密度 $(F R T D)=$ 细根干质量/细根体积; 小枝组织密 度 $(T T D)=$ 小枝干质量/小枝体积。

\section{3 数据分析}

对各个性状求算术平均值和标准偏差, 采用独 立样本 $t$ 检验比较不同生长型各性状的差异。利用变 异系数 $(C V)$ 计算各个功能性状的变异程度。利用单 因素方差分析方法检测生长型、生活型、物种对性 状变异的影响。以一般线性模型(GLM)检测单因子 作用的效应以及双因子和多因子交互作用的效应。 采用Pearson相关检验分析种间和种内各个功能性 状的相关性。所有统计分析在SPSS 20软件中完成。

\section{2 结果}

\section{1 植物性状总体变异特征}

喀斯特地区10种优势木本植物的性状总特征见 表2，其中FRTD、LA、SRL和 $L T$ 的变化范围最大。 在物种水平, 不同植物间的同一性状值大小差 别较大, 且不同性状有不同的权衡(图1)。在枝叶性 状中, 安顺润楠的 $L T$ 最大, 倒卵叶旌节花次之, 异 叶鼠李和小果蓄薇最小, 但 $S L A$ 和 $L T D$ 却是前两者 最小, 后两者最大。云南鼠刺的 $L A$ 最大, 异叶鼠李 的最小。窄叶石栋的 $L D M C$ 最大, 倒卵叶旌节花的 最小。云贵鹅耳柊的 TDMC 和异叶鼠李的TTD分别 最大, 但这两种性状却是倒卵叶旌节花最小。物种 水平的叶性状组合中, 随着 $L T D$ 升高, $L T$ 和 $L A$ 降低, $S L A$ 和 $L D M C$ 却升高。 $L A$ 越大, $S L A$ 越小, 但 $T T D$ 越大, $T D M C$ 也越大。根系性状中, 刺异叶花椒 $S R L$ 最大, 云南鼠刺最小, 化香树的FRTD最大, 而安顺润楠最 小。除FRTD外, 其他各性状值的大小在物种间均表 现出显著差异(图1)。

在生长型水平, 所有叶片性状在乔木、灌木和 藤本植物间差异显著 (仅乔木与灌木的 LTD除外), 但小枝与根系性状在3种生长型间却无显著差异(表 3)。 $L A 、 L T 、 T T D 、 F R T D$ 从乔木到灌木和藤本植物 逐渐减小, $S L A$ 却相反。灌木植物的 $L D M C$ 和 $L T D$ 最小, $T D M C$ 和 $S R L$ 最大, 但乔木的 $L D M C$ 和 TDMC大于藤 本植物, $L T D$ 与 $S R L$ 却相反(表3)。对常绿和落叶植物 而言, 除LTD之外的所有叶性状及小枝性状TDMC 均差异显著, 但叶与小枝组织密度和 2 种根系性状 均无显著差异。常绿植物的 $L T 、 L A$ 和 $S R L$ 大于落叶 植物, 其他6种性状则是落叶大于常绿植物(表3)。

表2 喀斯特森林优势木本植物的功能性状特征

Table 2 Characteristics of dominant woody plant functional traits in the karst forest

\begin{tabular}{|c|c|c|c|c|}
\hline $\begin{array}{l}\text { 性状 } \\
\text { Trait }\end{array}$ & $\begin{array}{c}\text { 平均值 } \pm \text { 标准偏差 } \\
\text { Mean } \pm S D\end{array}$ & $\begin{array}{c}\text { 最小值 } \\
\text { Minimum }\end{array}$ & $\begin{array}{c}\text { 最大值 } \\
\text { Maximum }\end{array}$ & $\begin{array}{c}\text { 变异系数 } \\
\text { Coefficient of variation (\%) }\end{array}$ \\
\hline 叶片厚度 Leaf thickness (mm) & $0.17 \pm 0.07$ & 0.03 & 0.33 & 39.41 \\
\hline 叶面积 Leaf area $\left(\mathrm{cm}^{2}\right)$ & $17.74 \pm 10.44$ & 2.15 & 69.28 & 58.85 \\
\hline 比叶面积 Specific leaf area $\left(\mathrm{cm}^{2} \cdot \mathrm{g}^{-1}\right)$ & $134.44 \pm 45.80$ & 55.35 & 281.34 & 34.07 \\
\hline 叶干物质含量 Leaf dry-matter content $\left(\mathrm{g} \cdot \mathrm{g}^{-1}\right)$ & $0.40 \pm 0.06$ & 0.28 & 0.69 & 14.79 \\
\hline 叶组织密度 Leaf tissue density $\left(\mathrm{g} \cdot \mathrm{cm}^{-3}\right)$ & $0.54 \pm 0.13$ & 0.27 & 1.07 & 24.07 \\
\hline 小枝干物质含量 Twig dry-matter content of branchlets (g.g ${ }^{-1}$ ) & $0.48 \pm 0.06$ & 0.37 & 0.64 & 11.67 \\
\hline 小枝组织密度 Twig tissue density $\left(\mathrm{g} \cdot \mathrm{cm}^{-3}\right)$ & $0.69 \pm 0.19$ & 0.28 & 2.50 & 27.53 \\
\hline 比根长 Specific root length $\left(\mathrm{cm} \cdot \mathrm{g}^{-1}\right)$ & $251.91 \pm 128.79$ & 54.56 & 987.41 & 51.12 \\
\hline 细根组织密度 Fine root tissue density $\left(\mathrm{g} \cdot \mathrm{cm}^{-3}\right)$ & $0.85 \pm 0.82$ & 0.12 & 7.33 & 96.47 \\
\hline
\end{tabular}


A
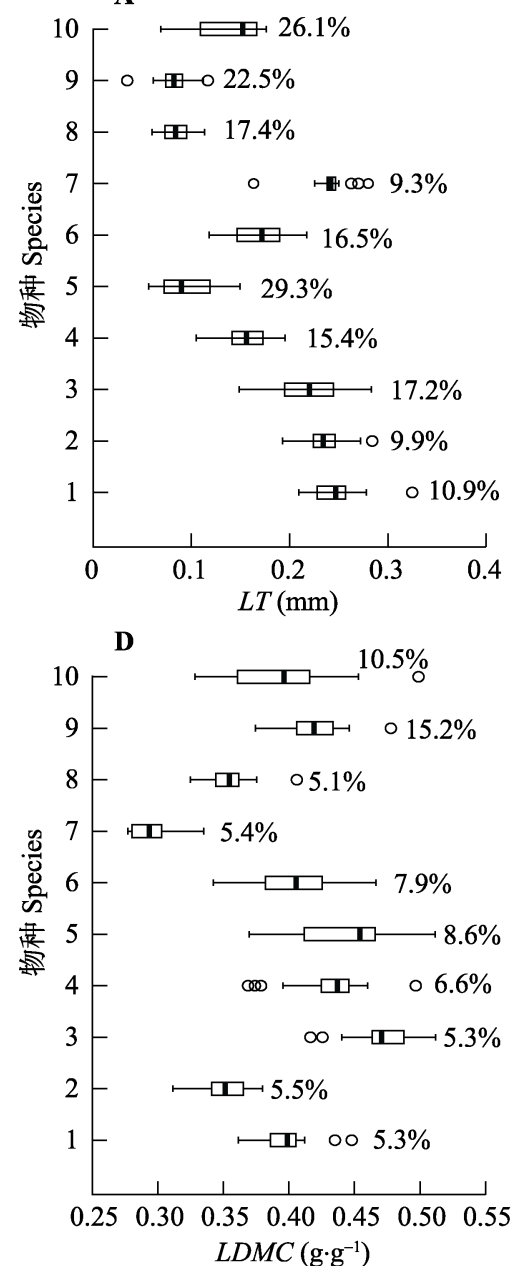

G

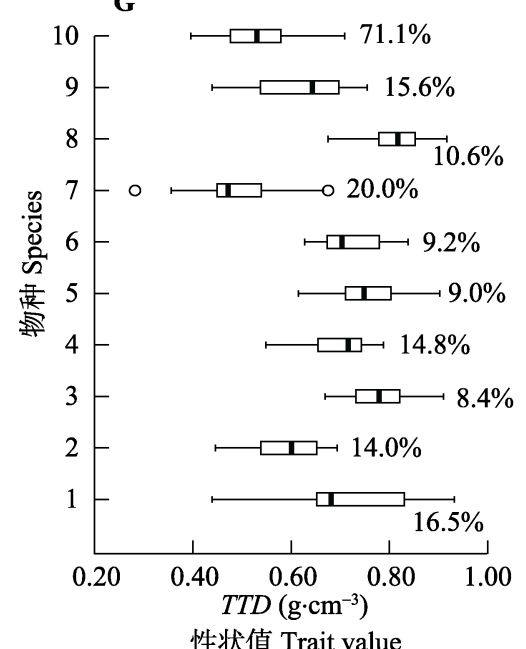

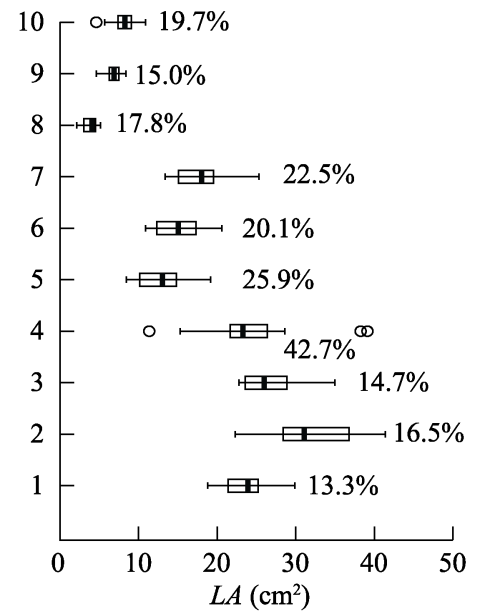

$\mathbf{E}$

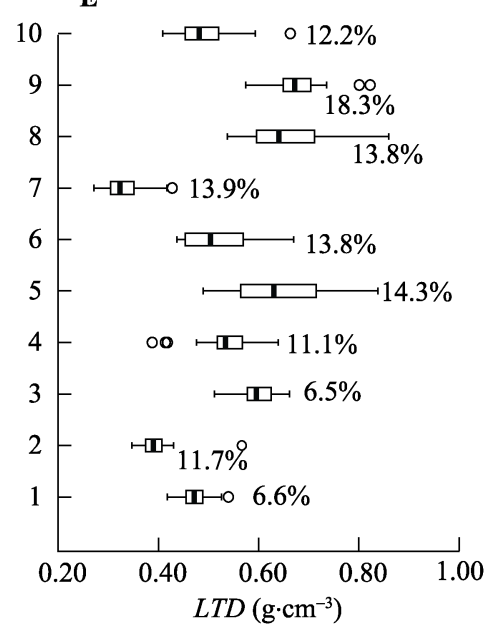

H

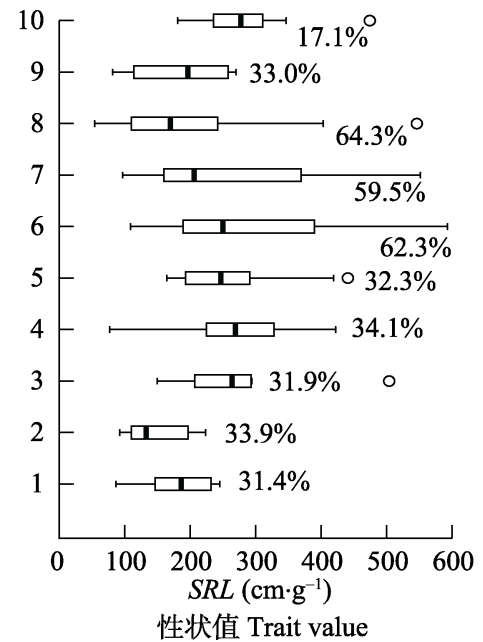

C

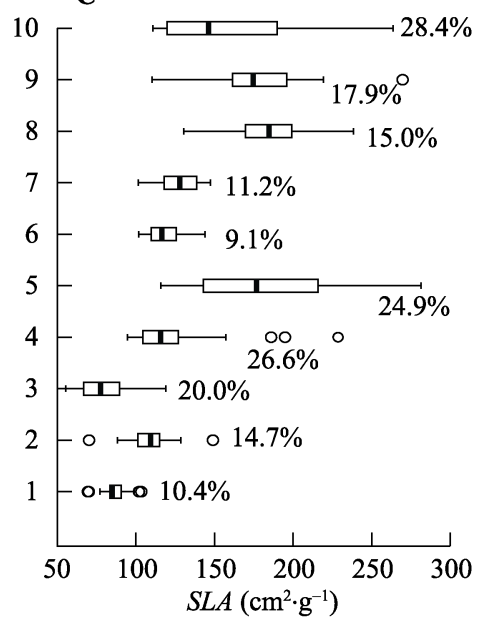

$\mathbf{F}$

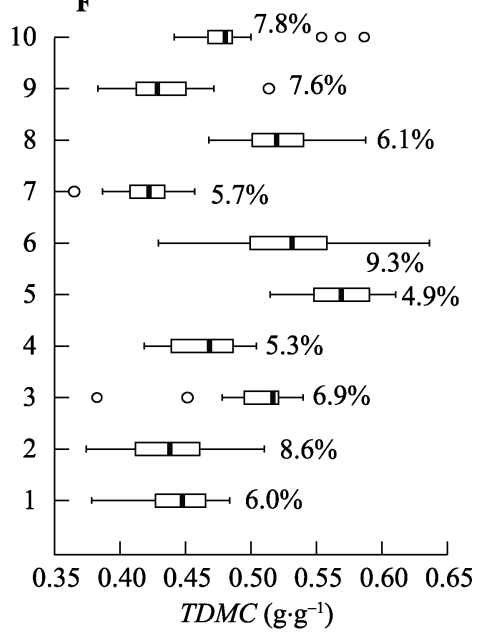

I

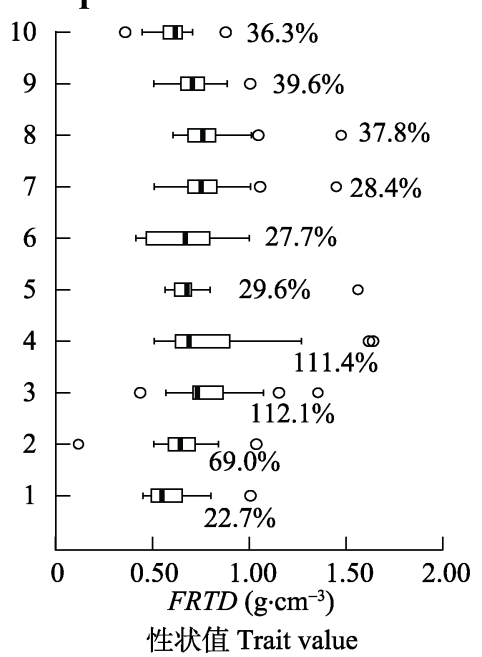

图1 喀斯特地区优势木本植物功能性状值。箱线图上的圆圈指示异常值; 图中百分数据为变异系数; 纵坐标的1-10代表 物种; 1, 安顺润楠; 2, 云南鼠刺; 3, 窄叶石栎; 4, 化香树; 5, 云贵鹅耳枋; 6, 刺异叶花椒; 7, 倒卵叶旌节花; 8, 异叶鼠李; 9, 小果蓄薇; 10 , 藤黄檀。 $\mathbf{A}$, 叶片厚度 $(L T)$ 。 $\mathbf{B}$, 叶面积 $(L A)$ 。 , 比叶面积 $(S L A)$ 。 , 叶片干物质含量 $(L D M C)$ 。 密度 $(L T D)$ 。 $\mathbf{F}$, 小枝干物质含量 $(T D M C)$ 。 $\mathbf{G}$, 小枝组织密度 $(T T D)$ 。 $\mathbf{H}$, 比根长 $(S R L)$ 。 , 细根组织密度 $(F R T D)$ 。

Fig. 1 Functional traits value of dominant woody species in the karst forest. The circle in the box plot indicates the abnormal value; the percentage of data in the figure is the coefficient of variation; $1-10$ represent species in the ordinate; the species number 1 , $M a-$ chilus cavaleriei; 2, Itea yunnanensis; 3, Lithocarpus confinis; 4, Carpinus pubescens; 5, Platycarya strobilacea; 6, Zanthoxylum ovalifolium; 7, Rhamnus heterophylla; 8, Stachyurus obovatus; 9, Rosa cymosa; 10, Dalbergia hancei. A, leaf thickness (LT). B, leaf area $(L A)$. C, specific leaf area $(S L A)$. D, leaf dry-matter content ( $L D M C)$. E, leaf tissue density ( $L T D)$. F, twig dry-matter content of branchlets (TDMC). G, twig tissue density (TTD). H, specific root length (SRL). I, fine root tissue density (FRTD). 
表3＼cjkstart不同生长型和生活型的植物性状(平均值土标准偏差)及(种间/种内)变异系数

Table 3 Plant functional traits in different growth and life forms (mean $\pm S D$ ) and (interspecific-intraspecific) coefficient of variation

\begin{tabular}{|c|c|c|c|c|c|c|c|c|c|}
\hline & $L T(\mathrm{~mm})$ & $L A\left(\mathrm{~cm}^{2}\right)$ & $\operatorname{SLA}\left(\mathrm{cm}^{2} \cdot \mathrm{g}^{-1}\right)$ & $L D M C\left(\mathrm{~g} \cdot \mathrm{g}^{-1}\right)$ & $\operatorname{LTD}\left(\mathrm{g} \cdot \mathrm{cm}^{-3}\right)$ & $\operatorname{TDMC}\left(\mathrm{g} \cdot \mathrm{g}^{-1}\right)$ & $T T D\left(\mathrm{~g} \cdot \mathrm{cm}^{-3}\right)$ & $S R L\left(\mathrm{~cm} \cdot \mathrm{g}^{-1}\right)$ & FRTD $\left(\mathrm{g} \cdot \mathrm{cm}^{-3}\right)$ \\
\hline 乔木 Tree & $\begin{array}{l}0.19 \pm 0.06^{\mathrm{a}} \\
(33.25 \% / \\
16.52 \%)\end{array}$ & $\begin{array}{l}24.66 \pm 9.02^{\mathrm{a}} \\
(36.59 \% / \\
22.63 \%)\end{array}$ & $\begin{array}{l}115.64 \pm 44.16^{\mathrm{a}} \\
(28.18 \% / \\
19.33 \%)\end{array}$ & $\begin{array}{l}0.42 \pm 0.05^{\mathrm{a}} \\
(11.59 \% / \\
6.26 \%)\end{array}$ & $\begin{array}{l}0.53 \pm 0.10^{\mathrm{a}} \\
(19.19 \% / \\
10.05 \%)\end{array}$ & $\begin{array}{l}0.48 \pm 0.06^{\mathrm{a}} \\
(11.48 \% / \\
6.36 \%)\end{array}$ & $\begin{array}{l}0.71 \pm 0.11^{\mathrm{a}} \\
(15.50 \% / \\
12.52 \%)\end{array}$ & $\begin{array}{l}237.89 \pm 89.59^{\mathrm{a}} \\
(37.66 \% / \\
32.72 \%)\end{array}$ & $\begin{array}{l}0.90 \pm 0.93^{\mathrm{a}} \\
(102.97 \% / \\
68.94 \%)\end{array}$ \\
\hline 灌木 Shrub & $\begin{array}{l}0.16 \pm 0.06^{\mathrm{b}} \\
(41.51 \% / \\
14.41 \%)\end{array}$ & $\begin{array}{l}12.3 \pm 6.62^{\mathrm{b}} \\
(53.85 \% / \\
20.10 \%)\end{array}$ & $\begin{array}{l}143.49 \pm 35.369^{\mathrm{b}} \\
(24.64 \% / \\
11.73 \%)\end{array}$ & $\begin{array}{l}0.35 \pm 0.05^{\mathrm{b}} \\
(14.31 \% / \\
6.11 \%)\end{array}$ & $\begin{array}{l}0.50 \pm 0.15^{\mathrm{a}} \\
(30.47 \% / \\
13.83 \%)\end{array}$ & & $\begin{array}{l}0.68 \pm 0.17^{\mathrm{a}} \\
(24.70 \% / \\
13.26 \%)\end{array}$ & $\begin{array}{l}271.09 \pm 179.73^{\mathrm{a}} \\
(66.30 \% / \\
62.05 \%)\end{array}$ & $\begin{array}{l}0.88 \pm 0.89^{\mathrm{a}} \\
(100.61 \% / \\
31.27 \%)\end{array}$ \\
\hline 藤本 Liana & $\begin{array}{l}0.11 \pm 0.04^{c} \\
(35.94 \% / \\
24.26 \%)\end{array}$ & $\begin{array}{l}7.43 \pm 1.48^{\mathrm{c}} \\
(19.95 \% / \\
17.33 \%)\end{array}$ & $\begin{array}{l}169.689 \pm 40.13^{\mathrm{c}} \\
(23.65 \% / \\
23.17 \%)\end{array}$ & $\begin{array}{l}0.41 \pm 0.06^{\mathrm{c}} \\
(13.86 \% / \\
12.77 \%)\end{array}$ & $\begin{array}{l}0.61 \pm 0.15^{\mathrm{b}} \\
(24.52 \% / \\
15.23 \%)\end{array}$ & $\begin{array}{l}0.46 \pm 0.04^{\mathrm{b}} \\
(9.80 \% / \\
7.70 \%)\end{array}$ & $\begin{array}{l}0.63 \pm 0.32^{\mathrm{a}} \\
(50.94 \% / \\
43.33 \%)\end{array}$ & $\begin{array}{l}255.17 \pm 110.55^{\mathrm{a}} \\
(43.32 \% / \\
37.93 \%)\end{array}$ & $\begin{array}{l}0.69 \pm 0.21^{\mathrm{a}} \\
(30.37 \% / \\
25.04 \%)\end{array}$ \\
\hline $\begin{array}{l}\text { 常绿植物 } \\
\text { Evergreen }\end{array}$ & $\begin{array}{l}0.17 \pm 0.07^{\mathrm{d}} \\
(39.34 \% / \\
14.81 \%)\end{array}$ & $\begin{array}{l}18.15 \pm 10.18^{\mathrm{d}} \\
(56.12 \% / \\
17.12 \%)\end{array}$ & $\begin{array}{l}131.19 \pm 43.38^{\mathrm{d}} \\
(34.47 \% / \\
13.99 \%)\end{array}$ & $\begin{array}{l}0.39 \pm 0.06^{\mathrm{d}} \\
(16.29 \% / \\
7.06 \%)\end{array}$ & $\begin{array}{l}0.54 \pm 0.13^{\mathrm{d}} \\
(27.98 \% / \\
12.12 \%)\end{array}$ & $\begin{array}{l}0.48 \pm 0.05^{\mathrm{d}} \\
(11.73 \% / \\
7.17 \%)\end{array}$ & $\begin{array}{l}0.71 \pm 0.14^{\mathrm{d}} \\
(20.81 \% / \\
13.38 \%)\end{array}$ & $\begin{array}{l}238.14 \pm 145.15^{\mathrm{d}} \\
(60.95 \% / \\
45.90 \%)\end{array}$ & $\begin{array}{l}0.88 \pm 0.92^{\mathrm{d}} \\
(93.11 \% / \\
59.18 \%)\end{array}$ \\
\hline $\begin{array}{l}\text { 落叶植物 } \\
\text { Deciduous }\end{array}$ & $\begin{array}{l}0.14 \pm 0.04^{\mathrm{e}} \\
(29.49 \% / \\
23.57 \%)\end{array}$ & $\begin{array}{l}16.84 \pm 11.08^{\mathrm{e}} \\
(65.79 \% / \\
29.42 \%)\end{array}$ & $\begin{array}{l}145.85 \pm 41.79^{\mathrm{e}} \\
(30.12 \% / \\
26.66 \%)\end{array}$ & $\begin{array}{l}0.43 \pm 0.04^{\mathrm{e}} \\
(9.60 \% / \\
8.56 \%)\end{array}$ & $\begin{array}{l}0.55 \pm 0.08^{\mathrm{d}} \\
(16.58 \% / \\
12.52 \%)\end{array}$ & $\begin{array}{l}0.50 \pm 0.05^{\mathrm{e}} \\
(10.65 \% / \\
6.02 \%)\end{array}$ & $\begin{array}{l}0.72 \pm 0.27^{\mathrm{d}} \\
(36.91 \% / \\
31.61 \%)\end{array}$ & $\begin{array}{l}237.66 \pm 94.71^{\mathrm{d}} \\
(34.61 \% / \\
34.23 \%)\end{array}$ & $\begin{array}{l}0.91 \pm 0.963^{\mathrm{d}} \\
(102.4 \% 2 / \\
52.96 \%)\end{array}$ \\
\hline
\end{tabular}

不同字母的数值间差异显著。FRTD, 细根组织密度; $L A$, 叶面积; $L D M C$, 叶片干物质含量; $L T$, 叶片厚度; LTD, 叶片组织密度; SLA, 比叶面积; SRL, 比根长; TDMC, 小枝干物质含量; TTD, 小枝组织密度。

Different letters indicate significant differences. FRTD, fine root tissue density; $L A$, leaf area; $L D M C$, leaf dry-matter content; $L T$, leaf thickness; $L T D$, leaf tissue density; $S L A$, specific leaf area; $S R L$, specific root length; TDMC, twig dry-matter content of branchlets; TTD, twig tissue density.

\section{2 植物性状的种内与种间变异}

喀斯特地区木本植物功能性状的种内、种间变 化较大，且不同性状间存在差异(表3)。其中，云贵 我耳枥的 $L T$ 变异最大(变异系数 $29.27 \%$ ), 化香树的 LA (42.65\%)、藤黄檀的SLA (28.43\%)和TTD (71.06\%)、 小果菩薇的LDMC (15.17\%)和LTD (18.32\%)、刺异 叶花椒的TDMC (9.33\%)、异叶鼠李的SRL (64.3\%) 和窄叶石栋的FRTD $(112.12 \%)$ 变异最大。

从物种平均来看, 除了藤本植物的 $T T D$, 无论 是物种还是生长型与生活型, 根系性状种内变异最 高, 且种间差异较大, 叶大小及叶片与小枝组织密 度的种内变异中等, 唯有TTD在不同物种间差异较 大, 干物质含量的种内变异最低、物种间差异很小 (表3)。生长型间各性状的种内变异差异较大, $L T$ 、

$S L A$ 和 $L D M C$ 是藤本 $>$ 乔木 $>$ 灌木, 枝性状和组织密 度是藤本 $>$ 灌木 $>$ 乔木, 根系性状的 $S R L$ 是灌木 $>$ 藤 本 $>$ 乔木, FRTD是乔木>灌木>藤本。在不同生活型 间, 枝叶性状除TDMC外都是常绿>落叶植物, 而根
系性状则相反(表3)。

植物性状种间变异普遍高于种内变异。除了藤 本植物有特例外, 根系性状的种间变异最大, 叶片 大小与组织密度性状次之, 干物质含量性状最低 (表2)。在不同生长型中，灌木的叶片、小枝和根系 性状的种间变异通常较大，尤其叶片与根系性状; 藤本植物除了 $L T 、 L T D 、 T T D$ 和 $S R L$ 的种间变异高于 乔木植物外，其他性状都较低(表3)。对不同生活型 来说，常绿植物的种间变异通常高于落叶植物，但 在不同性状间有差别; $L A 、 T T D$ 和FRTD的种间变异 是常绿低于落叶植物，尽管二者间的差异不很显著， 其他性状却都是常绿高于落叶植物(表3)。

单因子方差分析(表4)表明物种差异对除TTD之 外的叶片与小枝性状变异的解释度均很高, 但对根 系性状与 $T T D$ 变异的解释度较低。不同生长型对性 状变异的影响程度都较小, 只对 $L A$ 与 $L D M C$ 两个叶 性状的影响相对较大。不同生活型对所有性状变异 几乎没有影响。生活型和生长型的交互作用对多数

表4 物种、生长型和生活型对性状变异的影响 $\left(R^{2}\right.$ 值)

Table 4 Effects of species, growth form and life form on trait variations ( $R^{2}$ value)

\begin{tabular}{|c|c|c|c|c|c|c|c|c|c|}
\hline 变量 Variables & $L T(\mathrm{~mm})$ & $L A\left(\mathrm{~cm}^{2}\right)$ & $S L A\left(\mathrm{~cm}^{2} \cdot \mathrm{g}^{-1}\right)$ & $L D M C\left(\mathrm{~g}^{\prime} \mathrm{g}^{-1}\right)$ & $L T D\left(\mathrm{~g} \cdot \mathrm{cm}^{-3}\right)$ & $T D M C\left(\mathrm{~g} \cdot \mathrm{g}^{-1}\right)$ & $\operatorname{TTD}\left(\mathrm{g} \cdot \mathrm{cm}^{-3}\right)$ & $S R L\left(\mathrm{~cm} \cdot \mathrm{g}^{-1}\right)$ & $F R T D\left(\mathrm{~g} \cdot \mathrm{cm}^{-3}\right)$ \\
\hline 物种 Species & 0.86 & 0.78 & 0.67 & 0.75 & 0.74 & 0.64 & 0.19 & 0.18 & 0.08 \\
\hline 生长型 Growth form & 0.13 & 0.50 & 0.16 & 0.31 & 0.02 & 0.06 & 0.03 & 0.02 & 0.01 \\
\hline 生活型 Life form & 0.08 & 0.01 & 0.03 & 0.12 & 0.01 & 0.04 & 0.00 & 0.02 & 0.00 \\
\hline 生长型×生活型 & 0.07 & 0.55 & 0.49 & 0.35 & 0.19 & 0.02 & 0.17 & 0.37 & 0.04 \\
\hline
\end{tabular}

Growth form $\times$ Life form

FRTD, 细根组织密度; $L A$, 叶面积; $L D M C$, 叶片干物质含量; $L T$, 叶片厚度; $L T D$, 叶片组织密度; SLA, 比叶面积; SRL, 比根长; TDMC, 小枝干物质含 量; TTD, 小枝组织密度。

FRTD, fine root tissue density; $L A$, leaf area; $L D M C$, leaf dry-matter content; $L T$, leaf thickness; $L T D$, leaf tissue density; $S L A$, specific leaf area; $S R L$, specific root length; TDMC, twig dry-matter content of branchlets; TTD, twig tissue density. 
性状变异的影响大于生活型和生长型的单独影响 (表4), 但是对 $L T 、 T D M C$ 和FRTD的影响不大。

\section{3 木本植物性状间的关联性}

相关性检验(表5)表明，除 $L A$ 与 $L D M C$ 之间外， 4 个叶性状间显著正或负相关, 小枝性状间也显著正 相关, 根系性状间却无相关性。除 $L A$ 和 SLA 与 TTD 外, 叶性状与枝性状间也大都显著相关。根系与枝 叶性状间只有 $S R L$ 与 $S L A 、 F R T D$ 与 $L A$ 显著负相关。 叶片与小枝间的组织密度和干物质含量显著正相关 (表5)。

\section{3 讨论和结论}

\section{1 喀斯特地区植物功能性状的变异特性}

本研究发现，黔中 10 种木本植物的 9 个功能性 状在种内与种间均存在不同程度的变异。很多研究 表明, 种间变异在植物功能性状变异中占据主导地 位, 但越来越多的证据表明种内变异也是不可忽视 的，可达总性状变异的 28\%-52\% (Albert et al., 2010; Auger \& Shipley, 2013; Jiang et al., 2016; 唐青青等, 2016)。黔中喀斯特地区植物性状的种内变异平均达 21\%, 相较于其他植被类型, 其性状种内变异幅度 较低, 这可能反映了严酷生境条件下较小形态可塑 性(Auger \& Shipley, 2013)。

不同环境条件下不同植物性状的种间变异具有 差异, 本研究中的 9 个性状种间变异幅度达 12\%-96\%，且根系性状的变异显著高于枝叶性状。 植物性状是由遗传因素与环境条件共同决定的(尧

表5 喀斯特森林 10 种优势木本植物功能性状之间的相关系数

Table 5 Correlation coefficient between plant functiolal traits of ten dominant woody species in the karst forest

\begin{tabular}{|c|c|c|c|c|c|c|c|c|}
\hline & $L T$ & $L A$ & $S L A$ & $L D M C$ & $L T D$ & $T D M C$ & $T T D$ & $S R L$ \\
\hline$L A$ & $0.65^{* *}$ & & & & & & & \\
\hline SLA & $-0.83^{* *}$ & $-0.56^{* *}$ & & & & & & \\
\hline$L D M C$ & $-0.21^{* *}$ & 0.01 & $-0.22^{* *}$ & & & & & \\
\hline$L T D$ & $-0.70^{* *}$ & $-0.47^{* *}$ & $0.34^{* *}$ & $0.64^{* *}$ & & & & \\
\hline$T D M C$ & $-0.38^{* *}$ & $0.41^{* *}$ & $0.17^{*}$ & $0.43^{* *}$ & $0.45^{* *}$ & & & \\
\hline$T T D$ & $-0.17^{*}$ & 0.10 & -0.02 & $0.28^{* * *}$ & $0.29^{* *}$ & $0.34^{* *}$ & & \\
\hline$S R L$ & 0.12 & -0.00 & $-0.18^{*}$ & 0.12 & -0.13 & 0.09 & 0.04 & \\
\hline FRTD & 0.02 & $-0.31^{* *}$ & -0.09 & 0.10 & 0.12 & 0.02 & -0.01 & -0.00 \\
\hline
\end{tabular}

$*, p<0.05 ; * *, p<0.01$. FRTD, 细根组织密度; LA, 叶面积; LDMC, 叶 片干物质含量; $L T$, 叶片厚度; $L T D$, 叶片组织密度; SLA, 比叶面积; $S R L$, 比根长; TDMC, 小枝干物质含量; TTD, 小枝组织密度。

FRTD, fine root tissue density; $L A$, leaf area; $L D M C$, leaf dry-matter content; $L T$, leaf thickness; $L T D$, leaf tissue density; $S L A$, specific leaf area; $S R L$, specific root length; TDMC, twig dry-matter content of branchlets; TTD, twig tissue density.

www.plant-ecology.com
婷婷等, 2010), 不同遗传背景的物种(分类单元不同) 其性状在种间差异较大, 尤其是叶性状(Ackerly \& Reich, 1999), 但枝干性状变异却相对较小, 在种间 表现较稳定(Garnier et al., 2001)。另一方面, 植物长 期适应于其生存环境, 其性状变异幅度随生境而异 (Westoby \& Wright, 2006), 尤其是根系所处的地下 生境更加复杂多样, 因此, 植物根系性状具有更大 的变异和不确定性(Comas \& Eissenstat, 2004)。

从不同生长型和生活型看, 灌木植物性状种间 变异大于乔木和藤本植物, 这可能与灌木所处的林 下环境多变, 不同种类对立地条件的适应存在较大 差异有关。常绿植物与落叶植物相比, 由于叶片构 建成本与叶习性的季节变化较大, 因此, 其 $L T$ 、 $S L A 、 L D M C 、 L T D 、 T D M C 、 S R L$ 的变异系数高于 落叶植物。这与唐青青等(2016)对常绿植物的叶性 状变异大于落叶植物的研究结论一致。

本研究还发现, 喀斯特地区植物功能性状的种 间变异, 尤其是枝叶性状, 主要受到物种类群(遗传 背景)的影响, 其次是生活型和生长型的交互作用 (表4), 但后者的生态学背景也是物种的分类单元, 因此，植物系统发育，亦即其进化与分类背景对性 状分异的影响很大, 有时候甚至超过环境因子的影 响(Figueroa \& Armesto, 2001; 陈林等, 2014; 苏文 华等, 2015; 陈文等, 2016)。然而, 物种类群对根系 性状变异的解释度较低, 这应该与喀斯特生境的高 度异质性密切相关(Ni et al., 2015; Liu et al., 2016), 其影响机制需要进一步研究。

\section{2 喀斯特地区植物不同器官功能性状的堣合}

植物生长和长期适应环境过程中受生理、系统 发育、环境等因素的综合作用, 各性状呈一定的相 关性(Kerkhoff et al., 2006; Wright et al., 2007), 最终 形成一系列适应特定环境的最佳功能性状组合 (Westoby et al., 2002)。本研究发现, 喀斯特地区植 物枝叶与根系性状的相关性较小, 枝叶性状间的相 关性显著。例如, $L T$ 与 $S L A$ 的负相关表明, 在干旱贫 痒的环境, 更多的叶片光合产物用于构建保卫组织 或增加叶肉密度, 以防止高温对叶片的损伤或水分 的丧失, 从而提高水分利用效率, 结果导致SLA减 小和 $L T$ 的增加(Comstock \& Mencuccini, 1998)。

研究表明, 干旱地区的物种通常有较厚的叶片 以适应水分胁迫, SLA减小, 叶片体积也随之减小, 导致LTD增大(Ohashi et al., 2006), 但是, 本研究结 
果正好相反, 表现为 $L T$ 与 $L T D$ 和 $L D M C$ 负相关, $S L A$ 与 $L T D$ 正相关, $L D M C$ 与 $L T D$ 正相关。 $L D M C$ 高和 $L T D$ 大的叶片相对坚韧, 对物理胁迫的抵抗力更强 (Cornelissen et al., 2003)。同时, TD反映植物器官中 生物量的累积状况(Reich et al., 1998), 本研究中 $L D M C$ 与 $L T D$ 正相关, 意味着对于喀斯特地区植物 而言, 更多的叶片光合产物被用来积累干物质, 从 而增强其对干旱生境的适合度(Niinemets, 2001)。

枝与叶大小紧密关联，枝大小变化可解释 $80 \%$ 以上的叶大小变异(Corner, 1949; Westoby \& Wright, 2003)。本研究中, TDMC与LA、SLA、LDMC、LTD, $T T D$ 与 $L D M C 、 L T D$ 均显著正相关, 这是由枝叶间的 权衡关系决定的, 其普遍存在于自然界。也有研究 发现, $S R L$ 和 $S L A$ 的相关性较弱, 并不存在于所有物 种中(Withington et al., 2006; 詹书侠等, 2016)。值得 提及的是, 本研究发现根系性状SRL 与叶性状SLA 显著负相关, 表明在喀斯特干旱环境下, 植物需提 高对水分和资源的吸收效率, 因此投入大量的生物 量用于生长根系, 而不是投入到叶片面积的扩展上, 这在喀斯特地区森林表现尤为突出(Ni et al., 2015)。

\section{3 喀斯特地区植物的环境适应策略}

本研究植物来自同一地点, 具有相似的生境和 资源, 但结果表明, 除了 FRTD, 其他 8 个性状在不 同物种中表现出显著差异。这不仅反映了不同种类 对局域环境的适应策略不同, 而且反映了共存物种 间由于竞争排斥导致的功能策略趋异(Zhang et al., 2010; 尧婷婷等, 2010)。

不同环境条件、相似功能群的植物功能性状也 具有不同的特征。桂林喀斯特地区灌从植被的优势 灌木具有较高的 $L T 、 L A$ 和 $L D M C$, 但 $S L A$ 显著低于本 研究(Jiang et al., 2016), 两地区的 $L T$ 和SLA存在显 著的差异 $(p<0.05), L A$ 与 $L D M C$ 差异不显著。两地同 属于喀斯特地貌, 但植被类型不同, 桂林是常绿和 落叶阔叶灌丛, 本研究对象是常绿与落叶阔叶林, 且灌木种不同, 林下环境也不同。桂林是灌从中的 灌木处于上木层, 本研究的灌木则为林下层。除此 之外, 气候因素也是两地区植物叶性状存在差异的 主要原因。与普定相比, 桂林纬度偏南, 海拔低, 年 平均气温高于普定 $4{ }^{\circ} \mathrm{C}$ 左右, 年降水量高 $600 \mathrm{~mm}$ 左右。普定地区云量大, 植物通过增大SLA来增强光 合作用以适应光照少的环境条件, 高 $S L A$ 体现了较 强的捕获光资源能力(陈文等, 2016)。重庆喀斯特地
区常绿植物的 $L D M C$ 和 $L T$ 大于本研究中的植物, $S L A$ 小于本研究植物, 而落叶植物的 3 个性状相反; 乔木树种的 LDMC、SLA大于本研究, 灌木树种的 $L D M C$ 大于本研究, SLA相反(刘宏伟等, 2014)。两地 区气候相近, 但重庆属低山峰丛, 贵州属高原型喀 斯特地貌, 且所研究树种不同, 植物性状也不同。

与同纬度的非喀斯特地区, 如浙江天童山(许 洺山等, 2016)、湖北星斗山(唐青青等, 2016)、广西 尧山(马姜明等, 2012)、云南和四川(苏文华等, 2015) 相比, 喀斯特地区和非喀斯特地区植物SLA、LA、 $L D M C$ 均表现出显著的差异性。普定喀斯特地区植 物的 SLA、LA小于非喀斯特地区植物, 而LTD、 $L D M C 、 T T D$ 和 TDMC大于非喀斯特地区植物。桂 林喀斯特地区植物的 $L T$ 显著高于同纬度非喀斯特 地区植物(Jiang et al., 2016), 而普定和重庆喀斯特 地区(刘宏伟等, 2015)的 $L T$ 稍小。非喀斯特地区植物 具有较大的 $S L A$ 和 $L A$, 体现了较强的捕获光能资源 能力, 能很好地适应资源丰富的环境。喀斯特土壤 水分季节性亏缺大, 严重影响了喀斯特地区植物的 生长发育, 因此经过长期干旱环境篮选, 喀斯特地 区植物形成了一套适应于干旱环境, 具有较小 $S L A$ 、 $L A$ 和较大 $L D M C 、 L T D$ 的叶性状组合。较小的 $S L A$ 和 $L A$ 有利于植物减小蒸腾作用, 保持水分, 从而保 持较低的生长速率, 而较大的 $L D M C$ 和 $L T D$ 有利于 植物储存营养物质(Wilson et al., 1999)。喀斯特地区 植物的 $L T$ 虽然不如干旱环境植物的 $L T$ 厚, 但叶片大 多数为革质叶或是较厚的纸质叶, 均有利于植物保 持水分。另外, 喀斯特地区植物SLA低, 比叶质量大, 对枝条的机械需求高, 因而拥有高的 $T T D$ 和 $T D M C$ 。

研究表明, 干旱或贫㾑环境中的植物通常有较 大的 $S R L$ 和较高的FRTD (Kramer-Walter et al., 2016), 表明在同等投资的情况下, 植物对养分和水分的吸 收能力较高(Bauhus et al., 2000)。相对于江西大岗山 的刨花楠(Machilus pauhoi)、山矾(Symplocos sumuntia)等(邹斌等, 2015)和武夷山的台湾松(Pinus taiwanensis) (郭炳桥, 2016), 喀斯特地区植物的SRL 显著较小, FRTD则显著较大。不言而喻, 喀斯特生 境中岩石裸露率高, 土层浅、土量少, 储水能力弱, 严重影响根系生长, 植物根系大多为浅根系类型, 因此, $S R L$ 显著小于其他地区。由于岩石挤压等因素, 喀斯特地区植物以增大FRTD的方式来满足根系对 水分和养分的需求。 
本研究结果表明, 普定喀斯特木本植物功能性 状既相互联系又存在较大的种内与种间差异, 与其 他类型的喀斯特地区植物, 尤其与同纬度地带的非 喀斯特地区植物相比, 普定喀斯特地区植物在枝叶 和根系器官发育形成了小 $L A 、 S L A$ 和 $S R L$, 大 $L D M C 、 T T D 、 T D M C$ 和 $F R T D$ 等一系列减小蒸腾和 储存养分的功能性状组合, 从而提高其对干旱贫㾑 的喀斯特环境的选择优势。

致谢 本研究得到中国科学院地球化学研究所环境 地球化学国家重点实验室开放课题(SKLEG2017911) 资助。感谢广西师范学院钟琳、梁传锋、庄世煊、 钟家坚等4位同学在野外和室内实验中提供的帮助, 感谢3位审稿人对本稿件的大力斧正。

\section{参考文献}

Ackerly DD, Reich PB (1999). Convergence and correlations among leaf size and function in seed plants: A comparative test using independent contrasts. American Journal of Botany, 86, 1272-1281.

Albert CH, Thuiller W, Yoccoz NG, Soudant A, Boucher F, Saccone P, Lavorel S (2010). Intraspecific functional variability: Extent, structure and sources of variation. Journal of Ecology, 98, 604-613.

Auger S, Shipley B (2013). Inter-specific and intra-specific trait variation along short environmental gradients in an old-growth temperate forest. Journal of Vegetation Science, 24, 419-428.

Bauhus J, Khanna PK, Menden N (2000). Aboveground and belowground interactions in mixed plantations of Eucalyptus globulus and Acacia mearnsii. Canadian Journal of Forest Research, 30, 1886-1894.

Bu WS, Schmid B, Liu XJ, Li Y, Hardtle W, von Oheimb G, Liang Y, Sun ZK, Huang YY, Bruelheide H, Ma KP (2017). Interspecific and intraspecific variation in specific root length drives aboveground biodiversity effects in young experimental forest stands. Journal of Plant Ecology, 10, 158-169.

Chave J, Coomes D, Jansen S, Lewis SL, Swenson NG, Zanne AE (2009). Towards a worldwide wood economics spectrum. Ecology Letters, 12, 351-366.

Chen L, Yang XG, Song NP, Yang XM, Xiao XP, Wang X (2014). A study on variations in leaf trait of 35 plants in the arid region of middle Ningxia, China. Acta Prataculturae Sinica, 23, 41-49. [陈林, 杨新国, 宋乃平 杨明秀, 肖绪培, 王兴 (2014). 宁夏中部干旱带主要植物叶性状 变异特征研究. 草业学报, 23, 41-49.]

Chen W, Wang JH, Ma RJ, Qi W, Liu K, Zhang LN, Chen XL (2016). Variance in leaf functional traits of 89 species from the eastern Guangdong of China. Chinese Journal of Ecology, 35, 2101-2109. [陈文, 王桔红, 马瑞君, 齐威, 刘坤, 张丽娜, 陈学林 (2016). 粤东89种常见植物叶功 能性状变异特征. 生态学杂志, 35, 2101-2109.]

Comas LH, Eissenstat DM (2004). Linking fine root traits to maximum potential growth rate among 11 mature temperate tree species. Functional Ecology, 18, 388-397.

Comstock J, Mencuccini M (1998). Control of stomatal conductance by leaf water potential in Hymenoclea salsola (T. \& G.), a desert subshrub. Plant, Cell \& Environment, 21, 1029-1038.

Cornelissen JHC, Lavorel S, Garnier E, Diaz S, Buchmann N, Gurvich DE, Reich PB, ter Steege H, Morgan HD, van der Heijden MGA, Pausas JG, Poorter H (2003). A handbook of protocols for standardised and easy measurement of plant functional traits worldwide. Australian Journal of Botany, 51, 335-380.

Corner EJH (1949). The durian theory or the origin of the modern tree. Annals of Botany, 13, 367-414.

Craine JM, Lee WG, Bond WJ, Williams RJ, Johnson LC (2005). Environmental constraints on a global relationship among leaf and root traits of grasses. Ecology, 86, 12-19.

Díaz S, Hodgson JG, Thompson K, Cabido M, Cornelissen JHC, Jalili A, Montserrat-Martí G, Grime JP, Zarrinkamar F, Asri Y, Band SR, Basconcelo S, Castro-Díez P, Hamzehee GFB, Khoshnevi M, Pérez-Harguindeguy N, Pérez-Rontomé MC, Shirvany A, Vendramini F, Yazdani S, Abbas-Azimi R, Bogaard A, Boustani S, Charles M, Dehghan M, de Torres-Espuny L, Falczuk V, GuerreroCampo J, Thompson K, Hynd A, Jones G, Kowsary E, Kazemi-Saeed F, Maestro-Martínez M, Romo-Díez A, Shaw S, Siavash B, Villar-Salvador P, Zak MR (2004). The plant traits that drive ecosystems: Evidence from three continents. Journal of Vegetation Science, 15, 295-304.

Díaz S, Kattge J, Cornelissen JH, Wright IJ, Lavorel S, Dray B, Reu B, Kleyer M, Wirth C, Prentice IC, Garnier E, Bonisch G, Westoby M, Poorter H, Reich PB, Moles AT, Dickie J, Gillison AN, Zanne AE, Chave J, Wright SJ, Sheremetev SN, Jactel H, Baraloto C, Cerabolini B, Pierce S, Shipley B, Kirkup D, Casanoves F, Joswig JS, Günther A, Falczuk V, Rüger N, Mahecha MD, Gorné L (2016). The global spectrum of plant form and function. Nature, 529, 167-171.

Eissenstat DM, Wells CE, Yanai RD, Whitbeck JL (2000). Building roots in a changing environment: Implications for root longevity. New Phytologist, 147, 33-42.

Figueroa JA, Armesto JJ (2001). Community-wide germination strategies in a temperate rainforest of Southern Chile: Ecological and evolutionary correlates. Australian Journal of Botany, 49, 411-425.

Garnier E, Laurent G, Bellmann A, Debain S, Berthelier P, Ducout B, Roumet C, Navas ML (2001). Consistency of

www.plant-ecology.com 
species ranking based on functional leaf traits. New Phytologist, 152, 69-83.

Guo BQ (2016). Study on the Adaptation of Main Functional Fine Root Traits to the Altitude Gradient of Pinus taiwanensis. Master degree dissertation, Fujian Normal University, Fuzhou. [郭炳桥 (2016). 黄山松细根主要功能 性状对海拔梯度的适应规律研究. 硕士学位论文, 福建 师范大学, 福州.]

Guo K, Liu CC, Dong M (2011). Ecological adaptation of plants and control of rocky-desertification on karst region of Southwest China. Chinese Journal of Plant Ecology, 35, 991-999. [郭柯, 刘长成, 董鸣 (2011). 我国西南喀斯 特植物生态适应性与石漠化治理. 植物生态学报, 35, 991-999.]

Jiang Y, Chen XB, Ma JM, Liang SC, Huang J, Liu RH, Pan YF (2016). Interspecific and intraspecific variation in functional traits of subtropical evergreen and deciduous broadleaved mixed forests in karst topography, Guilin, Southwest China. Tropical Conservation Science, 9(4). DOI: 10.1177/1940082916680211.

Kerkhoff AJ, Fagan WF, Elser JJ, Enquist BJ (2006). Phylogenetic and growth form variation in the scaling of nitrogen and phosphorus in the seed plants. The American Naturalist, 168, E103-E122.

Kramer-Walter KR, Bellingham PJ, Millar TR, Smissen RD, Richardson SJ, Laughlin DC (2016). Root traits are multidimensional: Specific root length is independent from root tissue density and the plant economic spectrum. Journal of Ecology, 104, 1299-1310.

Laughlin DC (2014). The intrinsic dimensionality of plant traits and its relevance to community assembly. Journal of Ecology, 102, 186-193.

Lavorel S, Garnier E (2002). Predicting changes in community composition and ecosystem functioning from plant traits: Revisiting the Holy Grail. Functional Ecology, 16, 545-556.

Liu HW, Liu WD, Wang W, Chai J, Tao JP (2015). Leaf traits and nutrient resorption of major woody species in the karst limestone area of Chongqing. Acta Ecologica Sinica, 35, 4071-4080. [刘宏伟, 刘文丹, 王微, 柴捷, 陶建平 (2015). 重庆石灰岩地区主要木本植物叶片性状及养分 再吸收特征. 生态学报, 35, 4071-4081.]

Liu HW, Wang W, Zuo J, Tao JP (2014). Leaf traits of main plants on limestone area in Zhongliang Mountain. Journal of Southwest China Normal University (Natural Science Edition), 39, 50-55. [刘宏伟, 王微, 左娟, 陶建平 (2014). 中梁山石灰岩山地30种主要植物叶片性状研究. 西南大学学报(自然科学版), 39, 50-55.]

Liu LB, Wu YY, Hu G, Zhang ZH, Cheng AY, Wang SJ, Ni J (2016). Biomass of karst evergreen and deciduous broad-leaved mixed forest in central Guizhou Province, southwestern China: A comprehensive inventory of a 2 ha plot. Silva Fennica, 50, 1492. DOI: 10.14214/sf.1492.
Ma JM, Zhang XZ, Liang SC, Chen T, Huang QJ (2012). Leaf traits of common plants in Yaoshan Mountain of Guilin, China. Journal of Guangxi Normal University (Natural Science Edition), 30, 77-82. [马姜明, 张秀珍, 梁士楚, 陈婷, 黄秋菊 (2012). 桂林尧山常见植物叶片性状研 究. 广西师范大学学报(自然科学版), 30, 77-82.]

Meng TT, Ni J, Wang GH (2007). Plant functional traits, environments and ecosystem functioning. Journal of Plant Ecology (Chinese Version), 31, 150-165. [孟婷婷, 倪健, 王国宏 (2007). 植物功能性状与环境和生态系统功能. 植物生态学报, 31, 150-165.]

Messier J, Lechowicz MJ, McGill BJ, Violle C, Enquist BJ (2017). Interspecific integration of trait dimensions at local scales: The plant phenotype as an integrated network. Journal of Ecology, 105, 1775-1790.

Ni J, Luo DH, Xia J, Zhang ZH, Hu G (2015). Vegetation in karst terrain of southwestern China allocates more biomass to roots. Solid Earth, 6, 799-810.

Niinemets Ü (2001). Global-scale climatic controls of leaf dry mass per area, density, and thickness in trees and shurbs. Ecology, 82, 453-469.

Ohashi Y, Nakayama N, Saneoka H, Fujita K (2006). Effects of drought stress on photosynthetic gas exchange, chlorophyll fluorescence and stem diameter of soybean plants. Biologia Plantarum, 50, 138-141.

Reich PB, Walters MB, Ellsworth DS, Vose JM, Gresham C, Bowman WD (1998). Relationships of leaf dark respiration to leaf nitrogen, specific leaf area and leaf life-span: A test across biomes and functional group. Oecologia, 114, 471-482.

Reich PB, Wright IJ, Cavender-Bares J, Craine JM, Oleksyn J, Westoby M, Walters MB (2003). The evolution of plant functional variation: Traits, spectra, and strategies. Internatinal Journal of Plant Sciences, 164, S143-S164.

Siefert A, Violle C, Chalmandrier L, Albert CH, Taudiere A, Fajardo A, Aarssen LW, Baraloto C, Carlucci MB, Cianciaruso MV, Dantas VD, DeBello F, Duarte LDS, Fonseca CR, Freschet GT, Gaucherand S, Gross N, Hikosaka K, Jackson B, Jung V, Kamiyama C, Katabuchui M, Kembel SW, Kichenin E, Kraft NJB, Lagerstrom A, Le BagoussePinguer Y, Li YZ, Mason N, Messier J, Nakashizuka T, McC Overton J, Peltzer DA, Perez-Ramos IM, Pillar VD, Prentice HC, Richardson S, Sasaki T, Schamp BS, Vandewalle M, Wardle DA (2015). A global meta-analysis of the relative extent of intraspecific trait variation in plant communities. Ecology Letters, 18, 1406-1419.

Stahl U, Kattge J, Reu B, Voigt W, Ogle K, Dickie J, Wirth C (2013). Whole-plant trait spectra of North American woody plant species reflect fundamental ecological strategies. Ecosphere, 4, 128.

Su WH, Shi Z, Yang B, Yang JJ, Zhao GH, Zhou R (2015). Intraspecific functional trait variation in a tree species 
(Lithocarpus dealbatus) along latitude. Plant Diversity and Resources, 37, 309-317. [苏文华, 施展, 杨波, 杨建军, 赵冠华, 周睿 (2015). 滇石柇沿纬度梯度叶片功能性状 的种内变化. 植物分类与资源学报, 37, 309-317.]

Tang QQ, Huang YT, Ding Y, Zang RG (2016). Interspecific and intraspecific variation in functional traits of subtropical evergreen and deciduous broad-leaved mixed forests. Biodiversity Science, 24, 262-270. [唐青青, 黄永涛, 丁 易, 藏润国 (2016). 亚热带常绿落叶阔叶混交林植物功 能性状的种间和种内变异. 生物多样性, 24, 262-270.]

Verheijen LM, Aerts R, Bonisch G, Kattge J, van Bodegom PM (2016). Variation in trait trade-offs allows differentiation among predefined plant functional types: Implications for predictive ecology. New Phytologist, 209, 563-575.

Violle C, Navas M-L, Vile D, Kazakou E, Fortunel C, Hummel I, Garnier E (2007). Let the concept of trait be functional! Oikos, 116, 882-892.

Violle C, Enquist BJ, McGill BJ, Jiang L, Albert CH, Huishof C, Jung V, Messier J (2012). The return of the variance: Intraspecific variability in community ecology. Trends in Ecology \& Evolution, 27, 244-252.

Walker AP, Beckerman AP, Gu LH, Kattge J, Cermusak LA, Domingues TF, Scales JC, Wohlfahrt G, Wullschleger SD, Woodward FI (2014). The relationship of leaf photosynthetic traits $-V_{\text {cmax }}$ and $J_{\max }-$ to leaf nitrogen, leaf phosphorus, and specific leaf area: A meta-analysis and modeling study. Ecology and Evolution, 4, 3218-3235.

Wang SJ, Li YB, Li RL (2003). Karst rocky desertification: Formation background, evolution and comprehensive taming. Quaternary Sciences, 23, 657-666. [王世杰, 李 阳兵, 李瑞玲 (2003). 喀斯特石漠化的形成背景、演化 与治理. 第四纪研究, 23, 657-666.]

Westoby M, Falster DS, Moles AT, Vesk PA, Wright IJ (2002). Plant ecological strategies: Some leading dimensions of variation between species. Annual Review of Ecology and Systematics, 33, 125-159.

Westoby M, Wright IJ (2003). The leaf size-twig size spectrum and its relationship to other important spectra of variation among species. Oecologia, 135, 621-628.

Westoby M, Wright IJ (2006). Land-plant ecology on the basis of functional traits. Trends in Ecology \& Evolution, 21, 261-268.

Wilson PJ, Thompson K, Hodgson JG (1999). Specific leaf area and leaf dry matter content as alternative predictors of plant strategies. New Phytologist, 143, 155-162.

Withington JM, Reich PB, Oleksyn J, Eissenstat DM (2006). Comparisons of structure and life span in roots and leaves among temperate trees. Ecological Monographs, 76, 381397.

Wright IJ, Ackerly DD, Bongers F, Harms KE, IbarraManriquez G, Martine-Ramos M, Mazer SJ, MullerLandau HC, Paz H, Pitman NCA, Poorter L, Silman MR,
Vriesendrop CF, Webb CO, Westoby M, Wright SJ (2007). Relationships among ecologically important dimensions of plant trait variation in seven neotropical forests. Annals of Botany, 99, 1003-1015.

Wright IJ, Reich PB, Westoby M, Ackerly DD, Baruch Z, Bongers F, Cavender-Bares J, Chapin T, Cornelissen JHC, Diemer M, Flexas J, Garnier E, Groom PK, Gulias J, Hikosaka K, Lamont BB, Lee T, Lee W, Lusk C, Midgley JJ, Navas ML, Niinemets U, Oleksyn J, Osada N, Poorter H, Poot P, Prior L, Pyankov VI, Roumet C, Thonmas SC, Tjoelker MG, Veneklass EJ, Villar R (2004). The worldwide leaf economics spectrum. Nature, 428, 821-827.

Xi XQ, Zhao YJ, Liu YG, Wang X, Gao XM (2011). Variation and correlation of plant functional traits in karst area of central Guizhou Province, China. Chinese Journal of Plant Ecology，35，1000-1008. [习新强, 赵玉杰, 刘玉国, 王 欣, 高贤明 (2011). 黔中喀斯特山区植物功能性状的变 异与关联. 植物生态学报, 35, 1000-1008.]

Xu MS, Zhao YT, Yang XD, Shi QR, Zhou LL, Zhang QQ, Arshad A, Yan ER (2016). Geostatistical analysis of spatial variations in leaf traits of woody plants in Tiantong, Zhejiang Province. Chinese Journal of Plant Ecology, 40, 48-59. [许洺山, 赵延涛, 杨晓东, 史青茹, 周刘丽, 张 晴晴, Arshad A, 阎恩荣 (2016). 浙江天童木本植物叶 片性状空间变异的地统计学分析. 植物生态学报, 40, 48-59.]

Yao TT, Meng TT, Ni J, Yan S, Feng XH, Wang GH (2010). Leaf functional trait variation and its relationship with plant phylogenic background and the climate in Xinjiang Junggar Basin, NW China. Biodiversity Science, 18, 201-211. [尧婷婷, 孟婷婷, 倪健, 阎顺, 冯晓华, 王国 宏 (2010). 新疆准噶尔荒漠植物叶片功能性状的进化 和环境驱动机制初探. 生物多样性, 18, 201-211.]

Zhan SX, Zhen SX, Wang Y, Bai YF (2016). Response and correlation of above- and below-ground functional traits of Leymus chinensis to nitrogen and phosphorus additions. Chinese Journal of Plant Ecology, 40, 36-47. [詹书侠, 郑 淑霞, 王扬, 白永飞 (2016). 羊草的地上-地下功能性 状对氮磷施肥梯度的响应及关联. 植物生态学报, 40, 36-47.]

Zhang ZH, Hu G, Zhu JD, Luo DH, Ni J (2010). Spatial patterns and interspecific associations of dominant tree species in two old-growth karst forests, SW China. Ecological Research, 25, 1151-1160.

Zou B, Cai F, Zheng JM, Dai W (2015). Biomass vertical distribution of fine root and its traits of four tree species in subtropical natural forest. Journal of Northeast Forestry University, 43, 18-22. [邹斌, 蔡飞, 郑景明, 戴伟 (2015). 亚热带天然林 4 种树木细根生物量垂直分布和 主要功能性状的差异. 东北林业大学学报, 43, 18-22.]

责任编委: 阎恩荣 责任编辑: 王 崴

www.plant-ecology.com 